\title{
Regulation of porcine circovirus type 2-like particles expressed in baculovirus expression system
}

\author{
Yingjun Li, Xiaoping Yi, Yingping Zhuang ${ }^{*}$ (D) and Ju Chu
}

\begin{abstract}
Background: Porcine circovirus type 2 (PCV2) virus-like particles (VLPs) are an effective vaccine against post-weaning multisystemic wasting syndrome. Burst sequence (BS) and the chicken 5'-HS4 $\beta$-globin (HS4) insulator were used to improve the production of PCV2 VLPs in insect cells.

Results: BS was used to modify the polyhedron (polh) promoter, and the chicken HS4 insulator was inserted downstream of the target gene expression cassette. This enhanced effect was detected by EGFP, a generally used protein as reporter. The transcription-level analysis demonstrated that the double BS and the chicken HS4 insulator improved the transcription levels of the target genes. At the same time, the two regulatory elements also improved the PCV2 VLPs' expression. PCV2 VLPs' expression levels increased by 14 and $24 \%$ at $72 \mathrm{~h}$ p.i. Further research observed an additive effect when the double BS and the chicken HS4 insulator simultaneously acted on the expression of PCV2 VLPs, with the PCV2 VLPs' expression level increasing by $35 \%$ at $72 \mathrm{~h}$ p.i.
\end{abstract}

Conclusions: BS and HS4 insulator can be used to improve the production of PCV2 VLPs in insect cells.

Keywords: Porcine circovirus type 2, Virus-like particles, HS4 insulator, Burst sequence, Baculovirus infection, Recombinant protein production

\section{Background}

Porcine circovirus type 2, a member of the Circoviridae family, is a small, icosahedral, non-enveloped, singlestranded circovirus DNA virus (size $\sim 17 \mathrm{~nm}$ ) (Tischer et al. 1982). The PCV2 genome is dominated by two open reading frames (ORFs). ORF1 encodes the viral replication (Rep) protein, and ORF2 codes the 233- or 234-amino acid capsid (Cap) protein. The Cap protein is a major immunogen of PCV2. PCV2 is the primary causative agent of a group of diseases called porcine circovirus disease (PCVD) in swine. The most relevant diseases of PCVD are post-weaning multisystemic wasting syndrome (PMWS), porcine dermatitis and nephropathy syndrome (PDNS), and reproductive failure. Of these, PMWS has a serious economic impact on the world swine industry (Harding et al. 1998; Chae 2005; Segalés

*Correspondence: ypzhuang@ecust.edu.cn

State Key Laboratory of Bioreactor Engineering, East China University of Science and Technology, 130 Meilong Rd., 200237 Shanghai, China et al. 2005). PMWS often occurs in 5-12 weeks weaned piglets. Symptoms include wasting, dyspnea, visibly enlarged lymph nodes, and jaundice (Ellis et al. 1998; Harding 1996). PCV2 is a stable virus and has a strong tolerance for common detergents and disinfectants, making environments contaminated with PCV2 difficult to clean.

To control the PMWS epidemic in swine, efforts have been made to develop vaccines against PCV2. In recent years, an inactivated PCV2 vaccine in post-weaning piglets has shown clinical efficacy (Pogranichniy et al. 2004) and is commercially available. The experimental PCV2 vaccine prototypes include recombinant DNA vaccines and subunit vaccines, which are based on the PCV2 ORF2 gene. Related reports show that protection induced by the baculovirus-expressed Cap protein is better than that induced by the DNA vaccine. The former completely inhibits PCV2 replication (Blanchard et al. 2003), preventing viremia and effectively reducing the amount of 
pig fecal and nasal virus. In addition, it also stimulates the production of PCV2-specific neutralizing antibodies.

The baculovirus expression vector system (BEVS) has become a popular platform for protein expression. The Autographa californica multiple nucleopolyhedrovirus (AcMNPV) is commonly used. However, heterologous proteins are less highly expressed in BEVS than the wildtype AcMNPV polh protein (Sano et al. 2002). Many efforts have been made to improve the expression of heterologous genes in the BEVS. Experiments show that introducing the cis elements to baculovirus genome is an effective way.

VLP is composed of one or more structure proteins of a virus, has not viral nucleic acid, and has a similar morphology with the authentic virus. VLP is a specific class of vaccine. The VLP vaccine has many advantages, such as displaying antigenic epitopes in the correct conformation in a highly repetitive manner and eliciting both humoral and cell-mediated immune responses even with no requirement of adjuvant for vaccine (Grgacic and Anderson 2006; Chackerian 2007; Liu et al. 2012). Currently, Some VLP vaccines are licensed, and many others are in clinical development. GSK's Engerix ${ }^{\circledR}$ (hepatitis B virus, HBV) and Cervarix ${ }^{\circledR}$ (human papillomavirus, HPV) and Merck's Recombivax HB $^{\circledR}$ (HBV) and Co., Inc.'s Gardasil ${ }^{\circledR}$ (HPV) are widely used VLP vaccines in the market (Kushnir et al. 2012). Recombinant protein systems used for the production of VLP vaccines include Escherichia coli (E. coli), yeast, insect, mammalian, plant cell systems, and cell-free systems (Kushnir et al. 2012; Noad and Roy 2003). Among these expression systems, the insect cellbased expression system has been widely used for VLP production (Noad and Roy 2003; Yamaji 2014; Fernandes et al. 2013). Several VLP vaccines produced using insect cells, of which, human papillomavirus-like particle vaccine (Cervarix) has achieved industrial-scale manufacture (Cox 2012; Schiller et al. 2012).

Many studies have demonstrated that the PCV2 Cap protein has antigenic properties and can spontaneously assemble into VLPs when the PCV2 Cap protein is expressed in insect cells (Nawagitgul et al. 2000; Liu et al. 2008; Fan et al. 2007). Although the PCV2 VLP vaccine is available, because of the possible reason of the low expression of PCV2 VLPs, commercial promotion of the vaccine is not widespread. Establishing effective regulatory strategies to improve vaccine production has become an important research topic. Currently, PCV2 VLPs' expression in BEVS has been improved by adding P10UTR/Syn21 and TB expression cassette (Liu et al. 2015; López-vidal et al. 2015). Two regulatory elements were used in this study. The burst sequence, approximately $50 \mathrm{bp}$ long, is located between TAAG and the translation initiation site and is required for the burst of expression from the polh promoter. Studies on the different numbers of BSs in the polh promoter showed that a double BS in the polh promoter is optimal for insect cells, and increasing the number of BSs weakens the polh promoter in AcMNPV (Manohar et al. 2010). The exact reason of increasing heterologous protein activity in response to a moderate raise in the number of the BS may be increased transcriptional efficiency (Manohar et al. 2010). The other element is the chicken $5^{\prime}$-HS4 $\beta$-globin insulator, approximately $1.2 \mathrm{kbp}$ long. The chicken HS4 insulator improves the target gene expression by increasing the sensitivity of neighboring DNA to DNaseI when it is placed downstream of the polh promoter-directed foreign gene expression cassette in AcMNPV (Wang et al. 2009). In this study, we first identified that the two regulatory elements increased the EGFP protein expression level in the BEVS. Next, we studied the expression and regulation of the two regulatory elements for the PCV2 VLPs in the BEVS. Moreover, the two regulatory elements were combined and applied in the BEVS, thereby improving the expression level of PCV2 VLPs.

\section{Methods \\ Plasmids, media, insect cells cultivation, and virus}

pFastbachtb vector and E. coli DH10Bac were purchased from Invitrogen (USA). pMD-HS4, including the HS4 insulator, was a gift from Dr. Zhong, FuDan University. pMD-EGFP and pMD-Cap are kept in the laboratory. The Spodopterafrugiperda cell line (Sf9) was used to propagate baculoviruses and express the protein of interest. Sf9 cells were suspension cultured in Sf900 II media (Invitrogen, USA) at $27{ }^{\circ} \mathrm{C}$. Sf9 cells were routinely subcultured according to $1 \times 10^{6}$ cells $/ \mathrm{ml}$. In addition, Sf9 cells were infected at a density of $2 \times 10^{6} \mathrm{cells} / \mathrm{ml}$. The recombinant viral stocks were collected by centrifuging the infected Sf9 cells suspension at $500 \mathrm{~g}$ for $5 \mathrm{~min}$ to remove cells and large debris. All virus used for infection were at the second passage (P2). Virus titers were determined according to the end-point dilution protocol (O’Reilly et al. 1994).

\section{Modification of pFastbachtb vector}

The BS was included in the polh promoter. It was amplified from AcMNPV by PCR with primers BS-F (5' - AATCCGCGG(AaaI)CCGGGAAGCCGATC-3') and BS-R(CGCGGTCCG(CpoI)AGATCCGCGCCCGA ATATTTATAGGTTTTTTTATTACAAAACTGTTACGA AAACAGTGGTGgGACGgTATGAATAA). The italic sequence of BS-R indicates the region of the polh promoter that includes the BS. The amplified sequence was introduced into the AaaI and CpoI restriction sites of pFastbachtb to generate the plasmid pFa-2BS. An experimental flow chart is shown in Fig. 1. 


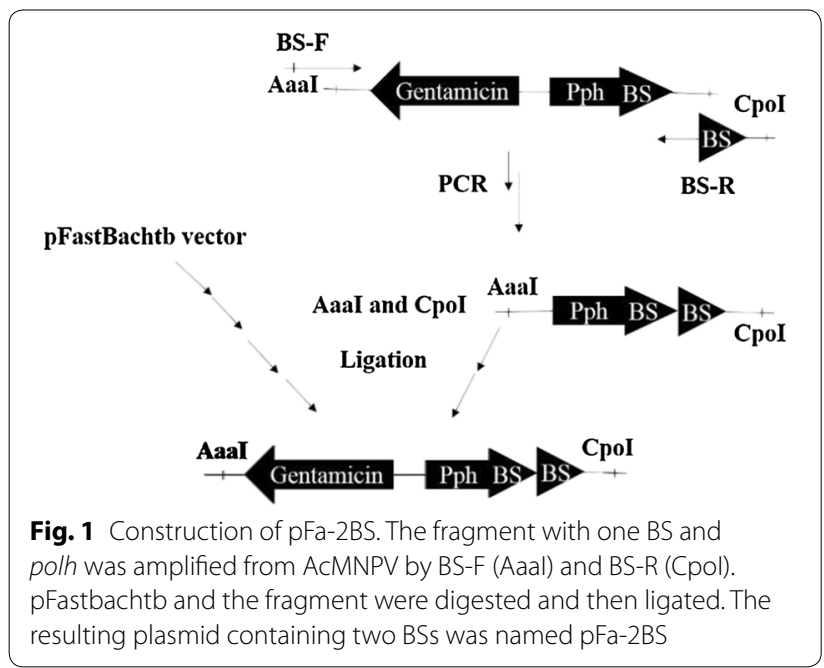

The chicken HS4 insulator sequence was amplified from pMD-HS4 with primers HSF (5'-TACCTAGG(BlnI) GAGCTCACGGGGACAGC-3') and HSR (5'-GACCT $A G G(\mathrm{BlnI})$ AATATTCTCACTGACTC). The chicken HS4 insulator was inserted into the BlnI site of pFastbachtb. We named the modified plasmids with the HS4 insulator sequence inserted in the same or opposite direction with the polh promoter as $\mathrm{pFa}-\mathrm{HS} 4$ and $\mathrm{pFa}-\mathrm{HS}^{-}{ }^{-}$, respectively.

\section{Construction of recombinant AcMNPV}

The EGFP (720 bp) gene amplified from pMD-EGFP and the cloning vectors were digested with BamHI and SalI. The EGFP gene was inserted into pFastbachtb and the constructed vector described above to generate the donor plasmids, such as pFa-EGFP, pFa-BS-EGFP, pFaEGFP-HS4, and pFa-EGFP-HS4 ${ }^{-}$. The structures of the donor plasmids are shown in Fig. 2. In the same way, the PCV2 ORF2 (702 bp) gene amplified from pMDCap. The donor plasmids, such as pFa-Cap, pFa-BS-Cap,
pFa-Cap-HS4, and pFa-Cap-HS4- ${ }^{-}$, were generated by inserting the amplified PCV2 ORF2 gene into pFastbachtb, pFa-BS, and pFa-HS4. The plasmid pFa-BSCap-HS4 was constructed on the basis of pFa-Cap-HS4. Recombinant baculoviruses, such as AcEGFP, AcBSEGFP, AcEGFP-HS4, AcEGFP-HS4 ${ }^{-}$and AcCap, AcBSCap, AcCap-HS4, AcCap-HS4 ${ }^{-}$, and AcBSCap-HS4, were constructed using the Bac-to-Bac ${ }^{\mathrm{TM}}$ system (Invitrogen, USA) following the manufacturer's protocol. At the same time, AcBlank was constructed using pFastbachtb as the donor, which was used as the blank control in this study.

\section{Detection of EGFP protein}

The $\mathrm{Sf} 9$ cells used in this work were healthy, with greater than $95 \%$ viability. AcBlank, AcEGFP, AcBSEGFP, AcEGFP-HS4, and AcEGFP-HS4- ${ }^{-}$infected the Sf9 cells at a multiplicity of infection (MOI) of 1 . The supernatant of the infected Sf 9 cells was collected at $72 \mathrm{~h}$ p.i. by centrifugation at $1000 \mathrm{~g}$. The infected cells were re-suspended in phosphate buffer saline (PBS) according to $2 \times 10^{5}$ cells/ $\mathrm{ml}$, and $100 \mu \mathrm{l}$ cell suspension was added into a well of a 96-well black plate. The fluorescence intensity was measured by the multi-functional microplate reader using 485 and $535 \mathrm{~nm}$ as the wavelength of excitation and emanation, respectively.

\section{Immunoblot}

AcCap-infected Sf9 cells were collected at 48 h p.i. The total protein from approximately $1 \times 10^{4}$ cells was separated through $12 \%$ SDS-PAGE and transferred onto a polyvinylidene fluoride (PVDF) membrane (Millipore Corporation, USA) at $300 \mathrm{~mA}$ for $90 \mathrm{~min}$. The membranes were blocked with $5 \%$ skim milk powder in PBST (PBS added $0.05 \%$ Tween20), incubated with mouse antiPCV2 Cap monoclonal antibody (Jiamay, CHN), and detected with HRP-conjugated goat anti-mouse (TIANGEN, Ger.).

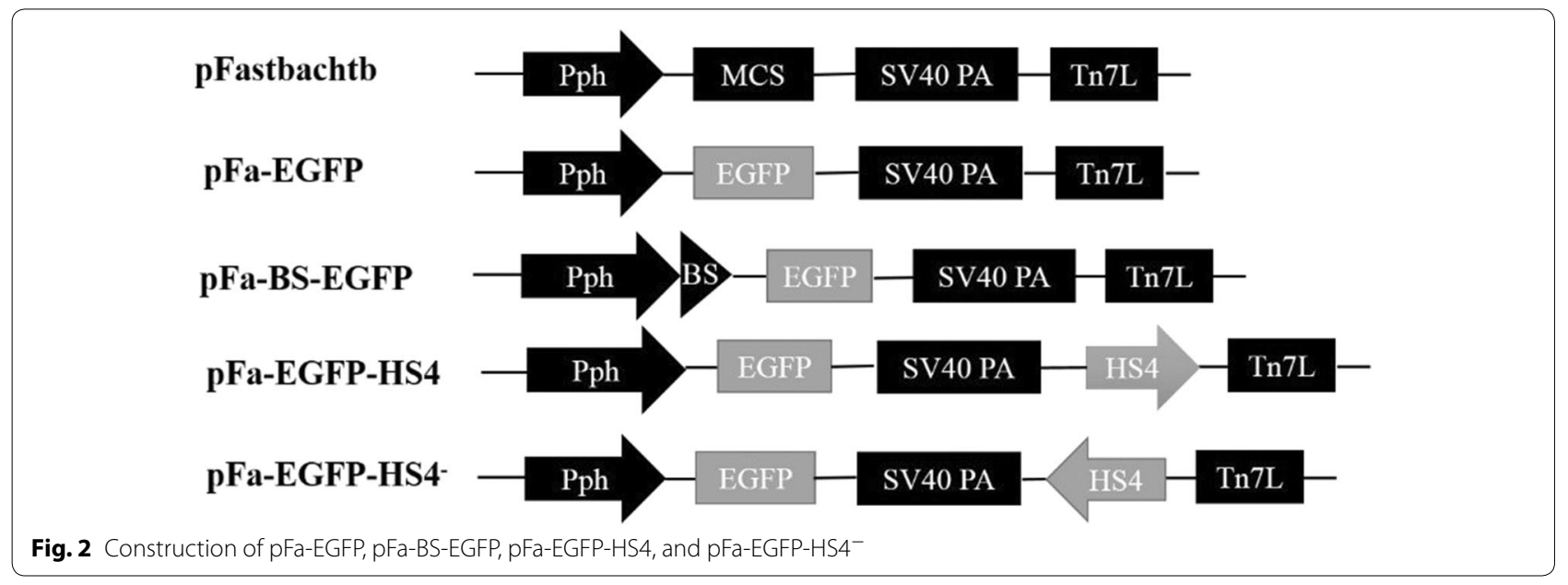




\section{Transmission electron microscopy}

To determine the ability of the PCV2 Cap protein expressed in insect cells to form VLPs, AcCap, AcBSCap, AcCap-HS4, AcCap-HS4- ${ }^{-}$, and AcBSCap-HS4-infected insect cells were lysed by an ultrasonic processor with a power of $200 \mathrm{w}$ and centrifuged at $12,000 \mathrm{~g}$ for $30 \mathrm{~min}$. The supernatant was then collected. First, the supernatant samples were placed on top of $40 \%$ sucrose in PBS and centrifuged at 270,000 $\mathrm{g}$ for $6 \mathrm{~h}$. The pellets were re-suspended in PBS for further purification (Fan et al. 2007). Then, the re-suspended solution was laid on top of $60 \%$ sucrose in PBS for another centrifugation according to the above condition. Finally, the pellet was dissolved in PBS for observation with transmission electron microscopy.

Partially purified PCV2 Cap protein was added onto copper grids for $2.5 \mathrm{~min}$ at room temperature. Then, the grids were stained with $3 \%$ phosphotungstic acid (PTA) for $2.5 \mathrm{~min}$ (Yin et al. 2010) and viewed using JEM1400.

\section{Transcriptional analysis}

AcEGFP, AcBSEGFP, and AcEGFP-HS4-infected Sf9 cells were collected at $48 \mathrm{~h}$ p.i. Total RNA was isolated from virus-infected Sf 9 cells by TRIzol (Life Technology, USA), a commercially available mixture of organic solvents. The detailed extraction steps followed the manufacturer's protocol. Primary complementary DNA (cDNA) was synthesized with RevertAid First Strand cDNA Synthesis Kit (Thermo Scientific, USA). Quantitative real-time PCR was performed using the $2 \times$ SYBR Select Master Mix (Life Technologies, USA). The reaction volume was $25 \mu \mathrm{l}$, including $1 \mu \mathrm{l} \mathrm{cDNA}, 0.75 \mu \mathrm{l} 10 \mathrm{mM}$ each forward and reverse primers, $12.5 \mu \mathrm{l}$ SYBR Select Master Mix, and $10 \mu \mathrm{l}$ $\mathrm{ddH}_{2} \mathrm{O}$. The real-time PCR protocol consisted of the initial denaturation at $95^{\circ} \mathrm{C}$ for $2 \mathrm{~min}$, followed by 40 cycles: $95{ }^{\circ} \mathrm{C}$ for $15 \mathrm{~s}, 60{ }^{\circ} \mathrm{C}$ for $1 \mathrm{~min}$. The forward and reverse primers of the EGFP were designed by the Primer Premier 5.0 software. The sequences of the primers are as follows:

GF: 5'-AGGAGCGCACCATCTTCTTC-3'.

GR: $5^{\prime}$ - TGCCGTTCTTCTGCTTGTCG-3'.

To determine the relative transcriptional level of the EGFP, real-time PCR data were analyzed by the $2^{-\triangle \triangle \mathrm{Ct}}$ method (Schmittgen and Livak 2008) using $\beta$-actin as a reference gene for normalization. The forward and reverse primers of the $\beta$-actin gene were as follows:

Actin-F: GAAATCGTTCGTGACATCAAGGAG.

Actin-R: CAAGAAGGAAGGCTGGAAGAGG.

The expected PCR product sizes were 201 and $183 \mathrm{bp}$ in length for EGFP and actin gene, respectively.

\section{Expression and detection of PCV2 Cap protein in insect cells}

To investigate the enhanced effect of double BS and HS4 insulator on the PCV2 Cap protein, Sf9 cells were infected with AcBlank, AcCap, AcBSCap,AcCapHS4,AcCap-HS4 ${ }^{-}$, and AcBSCap-HS4 at MOI $=1$. The infected Sf9 cells were collected at $72 \mathrm{~h}$ p.i. by centrifugation at $1000 \mathrm{~g}$. Then, the pellets were re-suspended in lysis buffer (PBS containing $1 \mathrm{mM}$ PMSF) at a concentration of $1 \times 10^{7}$ cells $/ \mathrm{ml}$. The protein was released from Sf9 cells by ultrasonic processor with a power of $200 \mathrm{w}$ followed by centrifugation at $12,000 \mathrm{~g}$ for $15 \mathrm{~min}$. The supernatant was collected for further quantitative analysis by direct ELISA.

The purified PCV2 Cap protein was purchased from Zhejiang Tongdian Biological Technology Co., Ltd, as the standard substance for the standard curve. The wells of the ELISA plate were coated with 1000, 500, $250,125,62.5$, and $31.25 \mathrm{ng} / \mathrm{ml}(100 \mu \mathrm{l} /$ well $)$ standard substance diluted in coating buffer and then incubated overnight at $4{ }^{\circ} \mathrm{C}$. After washing three times with PBST, $5 \%$ skim milk in PBS was added to the wells $(200 \mu \mathrm{l} /$ well) and incubated for $1 \mathrm{~h}$ at $37^{\circ} \mathrm{C}$. After washing three times, $100 \mu \mathrm{l} /$ well of 1:2000 diluted mouse antiPCV2 Cap monoclonal antibody (MAb) was added to the plates and incubated for $1 \mathrm{~h}$ at $37^{\circ} \mathrm{C}$. After washing three times, HRP-conjugated goat anti-mouse antibody was diluted 2000 times, added to the wells $(100 \mu \mathrm{l} /$ well), and incubated for $1 \mathrm{~h}$ at $37^{\circ} \mathrm{C}$. After washing four times, TMB solution was added to the plates $(100 \mu \mathrm{l} /$ well) for color development. The plates were incubated for $15 \mathrm{~min}$ at $37^{\circ} \mathrm{C}$. The reaction was ended by adding $2 \mathrm{M}$ sulfuric acid $(100 \mu \mathrm{l} /$ well $)$. The absorbance values were then read at $450 \mathrm{~nm}$ with a microplate reader.

\section{Statistical analysis}

The significant differences between viruses were analyzed with triplicate experiments by SPSS19.0 Statistics. Student's $t$ test was used to evaluate comparisons of means. Data were shown as mean \pm standard deviation (SD). A $p$ value less than 0.05 was considered significant.

\section{Results \\ Effects of the double BS and the chicken HS4 insulator on EGFP protein expression}

Fluorescence can be observed by fluorescence microscope in all samples expect AcBlank-infected cells, indicating that AcBlank cannot express EGFP protein. The fluorescence intensity of AcEGFP, AcBSEGFP, AcEGFPHS4, and AcEGFP-HS4 ${ }^{-}$-infected Sf9 cells is shown in Fig. 3a. With AcEGFP-infected cells as the control, the EGFP expression in AcBSEGFP and AcEGFP-HS4 increased by 24 and $32 \%$, respectively. The fluorescence intensity in AcEGFP-HS4 ${ }^{-}$had no significant change. Comparing EGFP mRNA from different recombinant virus-infected cells, the mRNA levels in AcBSEGFP and AcEGFP-HS4 increased by 31 and $71 \%$, respectively, 

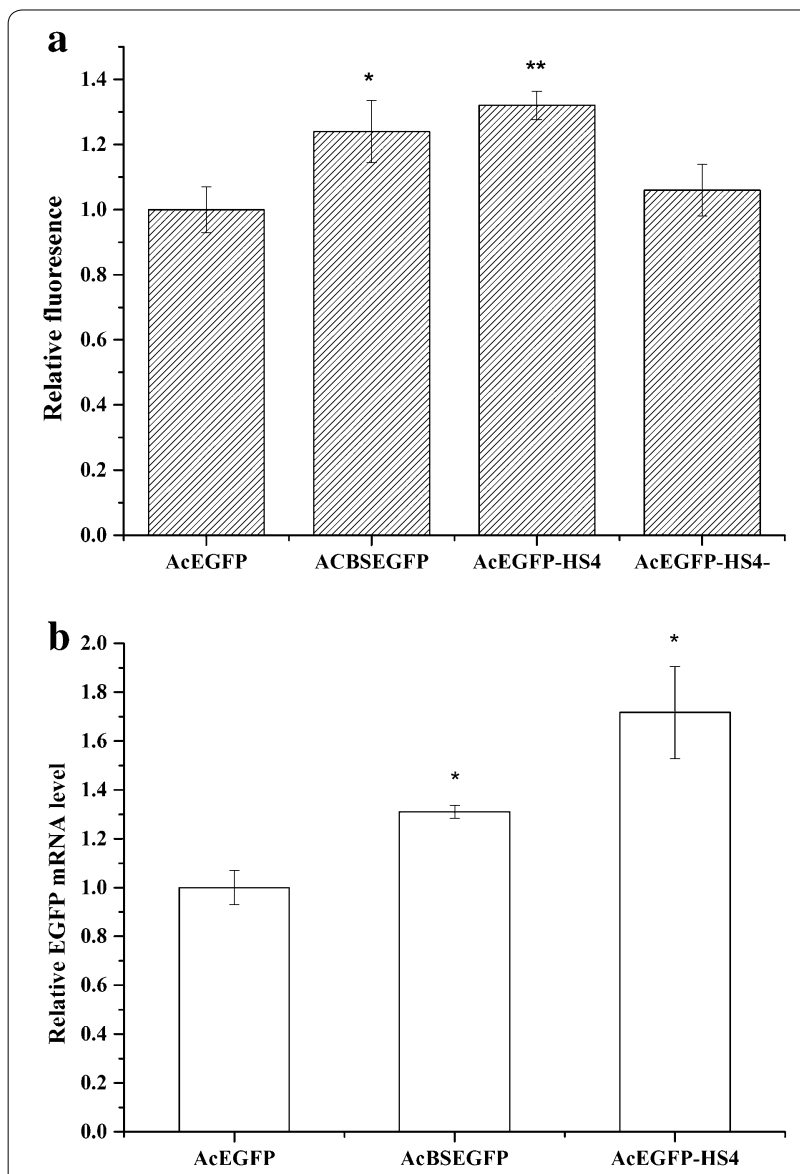

Fig. 3 Effect of BS and HS4 insulator on EGFP expression and the relative transcriptional analysis. a Fluorescence intensity of AcEGFP, AcBSEGFP, AcEGFP-HS4, and AcEGFP-HS4--infected Sf9 cells $72 \mathrm{~h}$ p.i. b Transcription of EGFP mRNA in AcEGFP, AcBSEGFP, and AcEGFPHS4-infected cells $48 \mathrm{~h}$ p.i. Error bars denote standard deviation $(n=3)$. Asterisks indicate a significant difference between viruses $\left({ }^{*} p<0.05 ;{ }^{* *} p<0.01\right)$

compared to AcEGFP (Fig. 3b). These results indicated that the increased EGFP transcriptional level was the main reason for the increased EGFP protein expression level.

In mammalian cells, $\beta$-actin gene is the commonly used reference gene. However, in BEVS, Baculovirus infection can selectively affect the expression of host cell genes (Rohrmann 2011). The possible reason is that viral factor can induce the host cells apoptosis in the late phase of viral infection. We chose $48 \mathrm{~h}$ p.i to detect the transcription level to avoid the inferior cell viability. In this experiment, the EGFP protein expression reached the maximum value at $72 \mathrm{~h}$. p.i (data not shown). The protein expression level was detected at $72 \mathrm{~h}$ p.i to compare the maximum yield of EGFP.

\section{Effects of the double BS and the chicken HS4 insulator on PCV2 VLPs' expression}

The Sf9 cells were infected with recombinant virus AcCap. PCV2 Cap protein expression was detected by Western blot (Fig. 4a). The results showed that a $28 \mathrm{kDa}$ band corresponding to the PCV2 Cap protein was present only in the AcCap-infected Sf9 cells and not in the AcBlank-infected and non-infected Sf9 cells. This indicated that the PCV2 Cap protein expressed by recombinant virus AcCap had the correct size and could be recognized by anti-Cap monoclonal antibody. To verify the correct assembly of PCV2 VLPs, transmission electron microscopy was used to observe the purified samples (Fig. 4b). The PCV2 VLPs were observed with similar morphology to the wild PCV2 particles. The diameter of PCV2 VLPs was approximately $17 \mathrm{~nm}$.

We established the direct ELISA to quantify the PCV2 Cap protein in this study. The method was used to determine the expression level of PCV2 Cap protein at $72 \mathrm{~h}$ p.i. in Sf9 cells infected by AcCap, AcBSCap, AcCap-HS4, and AcCap-HS4 ${ }^{-}$. The results showed that the expression
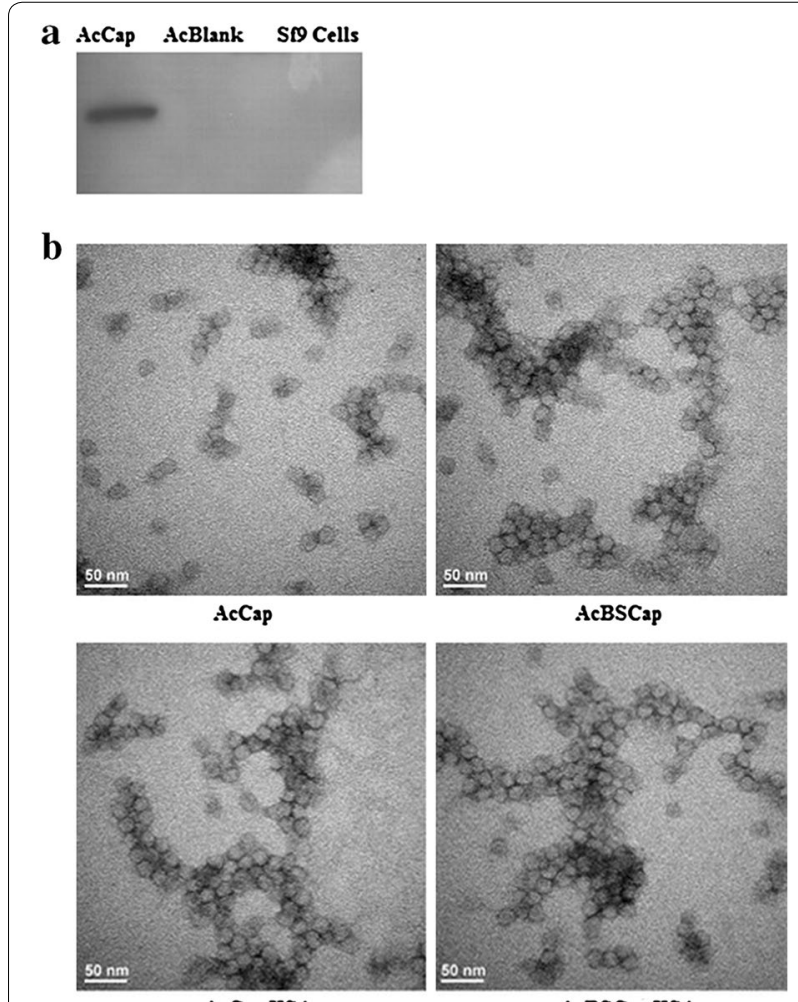

AcCap-HS4

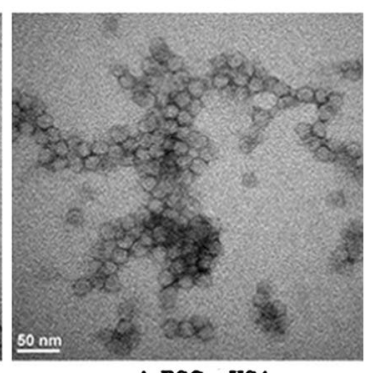

AcBSCap-HS4

Fig. 4 PCV2 VLPs expressed in Sf9 cells. a Western blotting analysis of the PCV2 Cap protein expressed in insect cells. b Electron micrographs of recombinant VLPS 
levels of PCV2 Cap protein in AcBSCap, AcCap-HS4, and AcCap-HS4 ${ }^{-}$were 554,605 , and $464 \mu \mathrm{g} / 10^{7}$ cells, respectively (Fig. 5). When AcCap was used as the control, AcBSCap increased by $14 \%$, AcCap-HS4 increased by $24 \%$, and AcCap- $\mathrm{HS}_{4}^{-}$reduced slightly.

The production of EGFP and Cap was increased by polh with double BS in Sf9 cells. However, the degree of foreign protein increase is lower than Manohar's report. The discrepancy may be due to the difference of insect cells and exogenous genes or to some uncharacterized factors. EGFP and Cap expression were improved when the chicken HS4 insulator sequence located in the downstream of the foreign gene expression cassette in AcMNPV. However, the results were significant ambiguity about the orientation of the chicken HS4 insulator in the BEVS. In our research, the recombinant virus AcEGFPHS4 with the chicken HS4 insulator in the same orientation increased EGFP and Cap expression. HS4 in the opposite orientation had no positive effect on EGFP and Cap expression, which were even slightly reduced. This result is opposite of the finding of Wang et al.

\section{The effect on PCV2 VLPs' expression of combining the double BS and the chicken HS4 insulator}

The double BS and the chicken HS4 insulator both improved the EGFP and PCV2 VLP expression. We, therefore, constructed recombinant baculoviruses AcBSCap-HS4 to investigate the interaction between the chicken HS4 insulator and the double BS in the BEVS. The results showed that the PCV2 VLPs' expression level significantly increased to $659 \mu \mathrm{g} / 10^{7}$ cells, an approximately $35 \%$ increase over the control (Fig. 5). This result confirmed that the two regulatory elements could work together without interference to improve the expression level of PCV2 VLPs.

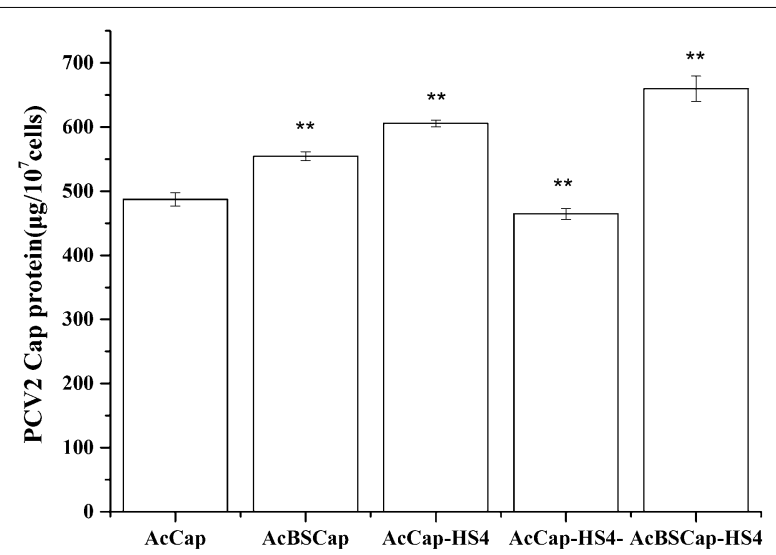

Fig. 5 Effect of BS and HS4 insulator on PCV2 Cap protein expression. Error bars denote standard deviation $(n=3)$. Double asterisks indicate a statistically significant difference $\left({ }^{* *} p<0.01\right)$

\section{Discussion}

As a potential vaccine candidate, VLP vaccines have many advantages, such as remarkable immunogenicity, safety, steady, and presentation of foreign antigens (Crisci et al. 2012). With the VLPs to be a potential vaccine, they need a suitable expression system to produce. BEVS is a common platform for foreign protein expression. A prominent characteristic of this expression system is the expression of viral structural proteins that can spontaneously form VLPs. BEVS for VLP vaccine production has many advantages. First, insect cells can be high-density suspension culture, and easily scale up. Second, baculovirus has a narrow host range, and is easily inactivated by chemical reagent. Finally, insect cell culture process greatly reduces the risk of culturing opportunistic pathogens (Liu et al. 2013). With the baculovirus preparation process becoming more convenient, researchers will focus on improving the expression levels of exogenous proteins by changing the baculovirus genome. Regulatory elements are increasingly studied, including the lobster tropomyosin cDNA sequence of L21 (Sano et al. 2002), the BS (Manohar et al. 2010), the chicken HS4 insulator sequence (Wang et al. 2009), and the hr1 sequence (Pikaart et al. 1998). At the same time, VLPs' expression and regulation through regulatory elements have become an important research topic.

The BS and chicken HS4 insulator were used in this study for the production of PCV2 VLPs. The BS is the $\mathrm{A} / \mathrm{T}$ rich sequence of the very late promoter (Venkaiah et al. 2004). Mutations in BS reduce protein expression by two- to 20-fold and lower both the RNA level and the rate of transcription initiation from the promoter (Ooi et al. 1989). The chicken HS4 insulator is one of the first identified and best-studied elements in mammalian cell lines. When the chicken HS4 insulator was integrated into an expression vector surrounded by a reporter gene, the protein was expressed steadily over time, but there was only modest increase of protein expression in CHOK1 cells (Pikaart et al. 1998; Izumi and Gilbert 1999). In recent years with the development of BEVS, the chicken HS4 insulator sequence was used in the BEVS to improve protein expression. The results showed that the reporter protein had an obvious increase when this element was integrated downstream of the polh promoter (Wang et al. 2009).

This study verified that the double BS and the chicken HS4 insulator effectively improved the expression level of EGFP protein in Sf9 cells. The transcription-level analysis found that both regulatory elements improved the transcription level of the target gene. The improvement of the EGFP transcriptional level may be the main reason for the improvement of the EGFP protein expression level. The results show that the two regulatory elements could 
also effectively improve the expression of PCV2 VLPs in Sf9 cells. In this study, EGFP as a report protein has a similar size with PCV2 Cap protein. Using the double BS to modify the polh promoter, the PCV2 VLPs' expression levels increased by $14 \%$. In addition, when HS4 insulator was used, the PCV2 VLPs' expression levels increased by $24 \%$. Further research found an additive effect when the double BS and the chicken HS4 insulator combination acted on the expression of PCV2 VLPs. Here, the PCV2 VLPs' expression level increased by $35 \%$. However, there was significant ambiguity about the orientation of the chicken HS4 insulator in the BEVS. In our research, the recombinant virus AcEGFP-HS4 with the chicken HS4 insulator in the same orientation increased EGFP expression. HS4 in the opposite orientation had no positive effect on EGFP expression, which was even slightly reduced. This result is opposite of the finding of Wang et al. (2009).

Overall, this study confirmed the regulatory role of the double BS, the chicken HS4 insulator, and the combination of both in promoting the expression of PCV2 VLPs in the BEVS. This finding provides a guideline not only for improving the yield of VLPs but also provides an effective means for the wide application of PCV2 VLP vaccine.

\section{Conclusions}

We first established the direct ELISA to quantify the PCV2 VLPs. The results showed that the PCV2 VLPs' expression level significantly increased to $659 \mu \mathrm{g} / 10^{7}$ cells, an approximately $35 \%$ increase over the control, when both the cis elements were combined in AcMNPV. This finding provides a guideline not only for improving the yield of VLPs, but also provides an effective means for the wide application of PCV2 VLP vaccine.

\begin{abstract}
Abbreviations
PCV2: porcine circovirus type 2; VLPs: virus-like particles; polh: polyhedron; Cap: capsid; PCVD: porcine circovirus disease; PMWS: post-weaning multisystemic wasting syndrome; PDNS: porcine dermatitis and nephropathy syndrome; BEVS: baculovirus expression vector system; AcMNPV: Autographa californica multiple nucleopolyhedrovirus; EGFP: enhanced green fluorescent protein; Sf9: Spodopterafrugiperda cell line; P2: the second passage; PBS: phosphate buffer saline; PVDF: polyvinylidene fluoride; PTA: phosphotungstic acid; CDNA: complementary DNA.
\end{abstract}

\section{Authors' contributions}

YJL carried out experiments and manuscript writing. XPY was responsible for experimental design and data analysis. JCH was responsible to account for al aspects of the work in ensuring that questions related to the accuracy. YPZH was responsible for the manuscript revision and confirming the final version to be published. All authors read and approved the final manuscript.

\section{Acknowledgements}

This work was supported by Grants from the Chinese National Programs for High Technology Research and Development (2015AA020801). We thank Dr. J. Zhong (FU, Shanghai, China) for providing HS4 insulator vector.

\section{Competing interests}

The authors declare that they have no competing interests.

Received: 20 February 2016 Accepted: 8 July 2016

Published online: 22 July 2016

\section{References}

Blanchard P, Mahé D, Cariolet R, Keranflec'h A, Baudouard MA, Cordioli P, Albina E, Jestin A (2003) Protection of swine against post-weaning multisystemic wasting syndrome (PMWS) by porcine circovirus type 2 (PCV2) proteins. Vaccine 21:4565-4575

Chackerian B (2007) Virus-like particles: flexible platforms for vaccine development. Expert Rev Vaccines 6:381-390

Chae C (2005) A review of porcine circovirus 2-associated syndromes and diseases. Vet J 169:326-336

Cox MMJ (2012) Recombinant protein vaccines produced in insect cells. Vaccine 30:1759-1766

Crisci E, Bárcena J, Montoya M (2012) Virus-like particles: the new frontier of vaccines for animal viral infections. Vet Immunol Immunopathol 148:211-225

Ellis J, Hassard L, Clark E, Harding J, Allan G, Willson P, Strokappe J, Martin K, McNeilly F, Meehan B, Todd D, Haines D (1998) Isolation of circovirus from lesions of pigs with post weaning multisystemic wasting syndrome. Can Vet J 39:44-51

Fan H, Ju C, Tong T, Huang H, Lv J, Chen H (2007) Immunogenicity of empty capsids of porcine circovirus type 2 produced in insect cells. Vet Res Commun 31:487-496

Fernandes F, Teixeira AP, Carinhas N, Carrondo MJT, Alves PM (2013) Insect cells as a production platform of complex virus-like particles. Expert Rev Vaccines 12:225-236

Grgacic EV, Anderson DA (2006) Virus-like particles: passport to immune recognition. Methods 40:60-65

Harding JC (1996) Post-weaning multisystemic wasting syndrome (PMWS): preliminary epidemiology and clinical presentation. Proc Am West Assoc Swine Pract 28:503

Harding JCS, Clark EG, Strokappe JH, Willson PI, Ellis JA (1998) Postweaning multisystemic wasting syndrome: epidemiology and clinical presentation. J Swine Health Prod 6:249-254

Izumi M, Gilbert DM (1999) Homogeneous tetracycline-regulatable gene expression in mammalian fibroblasts. J Cell Biochem 76:280-289

Kushnir N, Streatfield SJ, Yusibov V (2012) Virus-like particles as a highly efficient vaccine platform: diversity of targets and production systems and advances in clinical development. Vaccine 31:58-83

Liu LJ, Suzuki T, Tsunemitsu H, Kataoka M, Ngata N, Takeda N, Wakita T, Miyamura T, Li TC (2008) Efficient production of type 2 porcine circovirus-like particles by a recombinant baculovirus. Arch Virol 153:2291-2295

Liu F, Ge S, Li L, Wu X, Liu Z, Wang Z (2012) Virus-like particles: potential veterinary vaccine immunogens. Res Vet Sci 93:553-559

Liu F, Wu X, Li L, Liu Z, Wang Z (2013) Use of baculovirus expression system for generation of virus-like particles: success and challenges. Protein Expr Purif 90:104-116

Liu Y, Zhang Y, Yao L, Hao H, Fu X, Yang Z, Du E (2015) Enhanced production of porcine circovirus type 2(PCV2) virus-like particles in Sf9 cells by translational enhancers. Biotechnol Lett 37:1765-1771

López-vidal J, Gómez-Sebastián S, Bárcena J, Nuñez MC, Martínez-Alonso D, Dudognon B, Guijarro E, Escribano JM (2015) Improved production efficiency of virus-like particles by the baculovirus expression vector system. PLoS One. doi:10.1371/journal.pone.0140039

Manohar SL, Kanamasa S, Nishina T, Kato T, Park EY (2010) Enhanced gene expression in insect cells and silkworm larva by modified polyhedrin promoter using repeated burst sequence and very late transcriptional factor-1. Biotechnol Bioeng 107:909-916

Nawagitgul P, Morozov I, Bolin SR, Harms PA, Sorden SD, Paul PS (2000) Open reading frame 2 of porcine circovirus type2 encodes a major capsid protein. J Gen Virol 81:2281-2287

Noad R, Roy P (2003) Virus-like particles as immunogens. Trends Microbiol 11:438-444

O'Reilly DR, Miller LK, Luckow VA (1994) Titering virus stocks in baculovirus expression vectors: a laboratory manual. Oxford University Press, Oxford 
Ooi BG, Rankin C, Miller LK (1989) Downstream sequences augment transcription from the essential initiation site of a baculovirus polyhedrin gene. J Mol Biol 210:721-736

Pikaart MJ, Recillas-Targa F, Felsenfeld G (1998) Loss of transcriptional activity of a transgene is accompanied by DNA methylation and histone deacetylation and is prevented by insulators. Genes Dev 12:2852-2862

Pogranichniy RM, Yoon KJ, Yaeger M, Vaughn E, Stammer R, Roof M (2004) Efficacy of experimental inactivated PCV2 vaccines for preventing PMWS in CDCD pigs. Proc Annu Meet Am Assoc Swine Vet 35:443-444

Rohrmann GF (2011) Baculovirus molecular biology. United States National Library of Medicine, Bethesda

Sano Kl, Maeda K, Maeda Y (2002) Enhancement of protein expression in insect cells by a lobster tropomyosin cDNA leader sequence. FEBS Lett 532:143-146

Schiller JT, Castellsagué X, Garland SM (2012) A review of clinical trials of human papillomavirus prophylactic vaccines. Vaccine 30:132-138

Schmittgen TD, Livak KJ (2008) Analyzing real-time PCR data by the comparative $C(T)$ method. Nat Protoc 3:1101-1108
Segalés J, Allan GM, Domingo M (2005) Porcine circovirus diseases. Anim Health Res Rev 6:119-142

Tischer I, Gelderblom H, Vettermann W, Koch MA (1982) A very small porcine virus with circular single-stranded DNA. Nature 295:64-66

Venkaiah B, Viswanathan P, Habib S, Hasnain S (2004) An additional copy of the homologous region(hr1) sequence in the Autographa californica multinucleocapsid polyhedrosis virus genome promotes hyperexpression of foreign genes. Biochemistry 43:8143-8151

Wang X, Li L, Ding S, Huang X, Zhang J, Yin J, Zhong J (2009) Chicken HS4 insulator significantly improves baculovirus-mediated foreign gene expression in insect cells by modifying the structure of neighbouring chromatin in virus minichromosome. J Biotechnol 142:193-199

Yamaji H (2014) Suitability and perspectives on using recombinant insect cells for the production of virus-like particles. Appl Microbiol Biotechnol 98:1963-1970

Yin S, Sun S, Yang S, Shang Y, Cai X, Liu X (2010) Self-assembly of virus-like particles of porcine circovirus type 2 capsid protein expressed from Escherichia coli. Virol J 7:166

\section{Submit your manuscript to a SpringerOpen ${ }^{\circ}$ journal and benefit from:}

- Convenient online submission

- Rigorous peer review

- Immediate publication on acceptance

- Open access: articles freely available online

- High visibility within the field

- Retaining the copyright to your article 